\title{
Uma Abordagem Baseada em Definição de Requisitos e em Verificação e Validação para o Processo de Monitoração de Aquisição de Software
}

\author{
Fabio Pinheiro Abreu ${ }^{1}$, Pedro Porfírio Muniz Farias ${ }^{1}$, Adriano Bessa de Albuquerque ${ }^{1}$ \\ ${ }^{1}$ Universidade de Fortaleza - UNIFOR \\ Mestrado em Informática Aplicada - MIA \\ Av. Washington Soares, 1321 \\ CEP 60.811-341, Fortaleza-CE-Brasil \\ fabiopinheiroabreulgmail.com, porfirio@unifor.br, adrianoba@unifor.br
}

\begin{abstract}
Resumo. Um cenário cada vez mais freqüente tem sido organizações adquirirem serviços de desenvolvimento de software junto a fornecedores. Os processos de aquisição propostos preocupam-se prioritariamente com as atividades até a celebração do contrato. Em todas as fases do processo de aquisição, em especial na fase de monitoração da aquisição, a participação do contratante é fundamental na definição dos requisitos e na verificação e validação dos produtos gerados pelo fornecedor. Este trabalho tem como objetivo propor uma abordagem baseada em verificação e validação para o processo de monitoração de aquisição de serviços de desenvolvimento de software, baseado nos principais guias, normas e modelos que abordam o assunto.
\end{abstract}

\begin{abstract}
Organizations acquiring software development service from suppliers is an increasingly common scenario. The proposed software acquisition processes are concerned primarily with activities until the contract's signature. At all phases of the software acquisition process, especially in the monitoring phase, the contractor's participation is fundamental in defining the requirements and verifying and validating the products developed by the supplier. This paper aims to propose an approach based on verification and validation for the monitoring of software acquisition process based in main guidelines, standards and maturity models that address the subject.
\end{abstract}

\section{Introdução}

Atualmente as organizações têm adquirido cada vez mais soluções de tecnologia, obtendo serviços de desenvolvimento de software junto a fornecedores. A necessidade de se obter soluções atendendo a padrões de qualidade cada vez mais altos, com rapidez, a um custo baixo e com as tecnologias apropriadas é crescente. Isso se deve principalmente ao fato dessas organizações necessitarem de maior eficiência nas suas operações para competir em mercados caracterizados por fortes disputas (SEI, 2006).

Aquisição de serviços de desenvolvimento de software, entretanto, é um processo complexo principalmente devido às características dos requisitos necessários ao serviço e às condições envolvidas. Esse ambiente apresenta riscos para as partes envolvidas e é comum a ocorrência de sérios conflitos na relação entre contratantes e fornecedores de software (SOFTEX, 
2009). Para minimizar esses riscos, é fundamental a participação do contratante na definição dos requisitos e na verificação e validação dos produtos gerados pelo fornecedor.

De acordo com o Relatório do Caos apenas $32 \%$ dos projetos são considerados bem sucedidos, ou seja, o projeto foi concluído no prazo com orçamento previsto e com todos os requisitos inicialmente especificados. Um total de $44 \%$ dos projetos são considerados desafiados, ou seja, o projeto foi concluído, mas acima do orçamento previsto, além do prazo estimado e com menos requisitos que originalmente especificados. Os $24 \%$ dos projetos restantes são cancelados em algum ponto durante o ciclo de desenvolvimento. De acordo com o relatório, as três principais razões para que um projeto seja bem sucedido são: 1) envolvimento do usuário, 2) suporte da gerência executiva e 3) declaração clara dos requisitos. No contexto de projetos de aquisição, a complexidade é ainda maior devido ao fato de uma parte ou toda a execução do projeto ocorrer fora das instalações do contratante (STANDISH, 2009).

Um processo de aquisição de serviços de desenvolvimento de software pode ser dividido em duas etapas. A primeira etapa consiste de atividades necessárias até a celebração do contrato, por exemplo, definição do escopo, solicitação e avaliação de propostas, seleção de fornecedores e assinatura do contrato. A segunda etapa consiste de atividades relacionadas ao acompanhamento do contrato, por exemplo: execução dos serviços de desenvolvimento de software, verificação, validação e aceite dos produtos de trabalho gerados, e a gestão propriamente dita do contrato. Essa segunda etapa será denominada neste trabalho etapa de monitoração da aquisição.

Este trabalho propõe um processo de monitoração da aquisição considerando que o maior esforço em um processo de aquisição se concentra na monitoração do contrato com o fornecedor. A fase de monitoração é de fato o início do processo de desenvolvimento do software adquirido. É na fase de monitoração que os problemas entre contratante e fornecedor serão mais evidenciados. O fato de se realizar uma correta delimitação do escopo, uma seleção do fornecedor correto e uma celebração de contrato adequada são importantes para o sucesso da estratégia de aquisição, mas não são suficientes para garantir esse sucesso. Na fase de monitoração surgirão tanto os problemas das fases anteriores do processo de aquisição quanto os problemas oriundos do próprio desenvolvimento do software pelo fornecedor.

A abordagem proposta neste trabalho para o processo de monitoração da aquisição se diferencia das outras abordagens na importância dada a duas atividades principais: a primeira de definição de requisitos e a segunda de verificação e validação dos produtos gerados. Essas atividades são assumidas como fundamentais para fazer com que contratante e fornecedor estejam alinhados quanto aos objetivos e resultados do processo de monitoração. O processo destaca fortemente a necessidade do envolvimento do contratante na definição dos requisitos juntamente com o fornecedor e na verificação e validação dos artefatos gerados de acordo com essa definição. O processo destaca a forte ligação existente entre essas atividades de tal forma que aquilo que é definido deve ser exatamente o que será verificado e validado.

Outro diferencial deste trabalho é a utilização de uma abordagem iterativa, baseada em ciclos de pequenos intervalos de tempo, como forma de permitir um acompanhamento mais efetivo da monitoração, definição dos requisitos e da aceitação dos produtos de trabalhos. Uma ênfase é dada à co-responsabilidade entre contratante e fornecedor ao longo de todo o processo de monitoração, fator que é chave para o sucesso de uma estratégia de aquisição.

Nesse contexto, este trabalho tem como principal objetivo propor uma abordagem fortemente baseada no envolvimento do contratante nas fases de requisitos, verificação e validação 
para o processo de monitoração de aquisição de software baseado nas principais características dos guias, normas e modelos que abordam o assunto, incluindo Capability Maturity Model Integration - CMMI, eSourcing Capability Model - eSCM, Melhoria do Processo de Software Brasileiro - MPS.BR e Project Management Body of Knowledge - PMBOK (SEI, 2006, 2007; ITSQC, 2006; SOFTEX, 2009; PMI, 2009).

Este artigo está estruturado em 6 seções. A seção 2 apresenta os guias, normas, modelos e trabalhos pesquisados relacionados com monitoração de aquisição de software. A seção 3 apresenta as normas e modelos pesquisados relacionados com verificação e validação de software. A abordagem proposta está descrita na seção 4. A seção 5 detalha a validação realizada da abordagem proposta. Por fim, a seção 6 apresenta as principais conclusões e trabalhos futuros.

\section{Guias, Normas, Modelos para Monitoração de Aquisição de Software}

Várias iniciativas foram empreendidas com vistas a tornar o processo de monitoração da aquisição de serviços de desenvolvimento de software mais previsível e com melhores resultados para os envolvidos. Padrões específicos para grandes organizações adquirentes de software e normas internacionais que orientam relações técnicas e comerciais foram criados a partir dessas iniciativas. A seguir são listadas as seguintes iniciativas internacionais e uma nacional: SEI, ITSqc, PMI, ISO e MPS.BR. Alguns trabalhos relacionados baseados nessas iniciativas foram encontrados durante o levantamento bibliográfico. Eles também serão listados a seguir.

O Software Engineering Institute (SEI) é o líder na divulgação e promoção da melhoria dos processos de software através de modelos de capacidade. Os modelos mais conhecidos são o Capability Maturity Model (CMM) e a sua atualização mais recente, o Capability Maturity Model Integration (CMMI).

O Information Technology Services Qualification Center (ITSqc) desenvolveu modelos de capacidade para melhorar o relacionamento entre provedores de serviço e seus clientes: eSourcing Capability Model for Service Providers (eSCM-SP): modelo de contratação de serviços com foco nas organizações provedoras de serviço e eSourcing Capability Model for Client Organizations (eSCM-CL): modelo de contratação de serviços com foco nas organizações clientes;

O Project Management Institute (PMI) é outra importante organização que promove a melhoria dos processos de gerenciamento de projetos, programas e portfólio cujo principal produto é o Project Management Body Of Knowledge (PMBOK).

A International Organization for Standardization (ISO) é o organismo de normalização cuja norma ISO/IEC 15504 é uma das suas principais referências para avaliação e subcontratação de serviços de software (ISO 15504, 2002).

O Programa de Melhoria de Processo do Software Brasileiro (MPS.BR) é uma iniciativa para adequar a qualidade do processo de software principalmente das micro, pequenas e médias empresas aos padrões de qualidade aceitos internacionalmente. Um dos seus guias é direcionado a aquisição de serviços de software (SOFTEX, 2009).

Durante o levantamento bibliográfico foram encontrados alguns trabalhos relacionados que se basearam nos guias, normas e modelos apresentados anteriormente. Esses trabalhos implementaram os conceitos definidos nessas referências e propuseram abordagens para $o$ processo de aquisição de serviços de software com atividades pré e pós-celebração do contrato (ALVES e GUERRA, 2004; PINHEIRO, 2006; CARDOSO, 2006). 
O processo de monitoração da aquisição proposto adota várias boas práticas existentes nos guias, normas e modelos apresentados. Em relação aos trabalhos relacionados este trabalho se posiciona propondo um processo focado na etapa de monitoração da aquisição com fortes características de iteratividade e envolvimento do contratante e do fornecedor. Conforme mencionado na seção 1 a etapa de monitoração da aquisição é caracterizada pelas atividades póscelebração do contrato, atividades onde estão presentes os maiores riscos ao sucesso da aquisição e é requerido maior esforço por parte das organizações. O caráter iterativo e o forte envolvimento do contratante e do fornecedor na definição e entendimento dos requisitos são diferenciais do processo proposto que busca minimizar esses riscos e otimizar o esforço empreendido na monitoração.

\section{Normas e Modelos para Verificação e Validação de Software}

Algumas abordagens de verificação e validação de software foram definidas na literatura para que a mesma seja realizada de maneira organizada, disciplinada e seguindo um conjunto de atividades bem definidas. A seguir são listadas as seguintes referencias na literatura: ISO/IEC 12207, CMMI e MPS.BR. Alguns trabalhos relacionados baseados nessas referências foram encontrados durante o levantamento bibliográfico. Eles também serão listados a seguir.

A norma ISO/IEC 12207 define o processo de verificação como um processo de apoio cujo objetivo é determinar se os produtos desenvolvidos em uma determinada atividade atendem completamente os requisitos ou condições impostas a eles nas atividades anteriores do processo de desenvolvimento. A norma define validação como a confirmação, por exame e fornecimento de evidência objetiva, de que os requisitos específicos, para um determinado uso pretendido, são atendidos (ISO 12207, 2002).

Os modelos CMMI-DEV e CMMI-ACQ definem as áreas de processo Verificação, Validação, Verificação da Aquisição e Validação da Aquisição respectivamente como áreas do nível de maturidade 3 - Definido. No CMMI, a verificação tem como objetivo garantir que os produtos de trabalho selecionados atendem seus requisitos especificados enquanto que a validação tem como objetivo demonstrar que um produto ou serviço adquirido atende seu uso pretendido quando colocado no ambiente pretendido.

O modelo de referência do MPS.BR define os processos de Verificação e Validação como processos do nível de maturidade D - Definido. No MPS.BR, a verificação tem como objetivo confirmar que cada serviço e/ou produto de trabalho do processo ou do projeto atende apropriadamente os requisitos especificados enquanto que a validação tem como objetivo confirmar que um produto ou componente do produto atenderá seu uso pretendido quando colocado no ambiente para o qual foi desenvolvido.

Durante o levantamento bibliográfico foram encontrados alguns trabalhos relacionados que se basearam nas normas e modelos apresentados anteriormente. Esses trabalhos implementaram os conceitos definidos nessas referências e propuseram abordagens de verificação e validação para processos de desenvolvimento de software (BARRETO, 2006; MATIELLO, 2006).

O processo de monitoração da aquisição proposto adota várias boas práticas existentes nos guias, normas e modelos apresentados. Em relação aos trabalhos relacionados este trabalho se posiciona utilizando formalmente atividades de verificação e validação ao longo de um processo de monitoração de aquisição de software. É diferencial do processo proposto a verificação e 
validação desde produtos de trabalho intermediários até o produto final utilizando critérios objetivos previamente definidos e acordados entre contratante e fornecedor.

\section{Processo de Monitoração de Aquisição de Software Baseado em Definição de Requisitos e em Verificação e Validação}

Este trabalho propõe um processo de monitoração de aquisição fortemente baseado no envolvimento do usuário e na clareza dos requisitos. No ambiente de monitoração de aquisição de software podemos considerar o usuário como sendo o contratante. É fundamental que o contratante participe do processo de monitoração de aquisição de forma efetiva para maximizar a chance de sucesso do projeto. A abordagem proposta enfatiza as atividades de definição do entendimento dos requisitos e as atividades de verificação e validação como fatores críticos de sucesso para a monitoração de aquisição e conseqüentemente para o projeto. Considerando uma estratégia iterativa e incremental, no início de cada iteração contratante e fornecedor devem priorizar a definição do entendimento dos requisitos e critérios de verificação e validação a serem atendidos. Nessa atividade será obtido o comprometimento com o escopo adquirido e critérios de aceitação dos artefatos, minimizando assim lacunas de entendimento e conseqüentemente o não atendimento das necessidades da aquisição. Ao longo da iteração o fornecedor realizará o desenvolvimento do artefato e ambos, contratante e fornecedor, participarão de atividades de verificação e validação dos produtos gerados. A Figura 1 apresenta o ciclo fundamental das atividades do processo proposto.

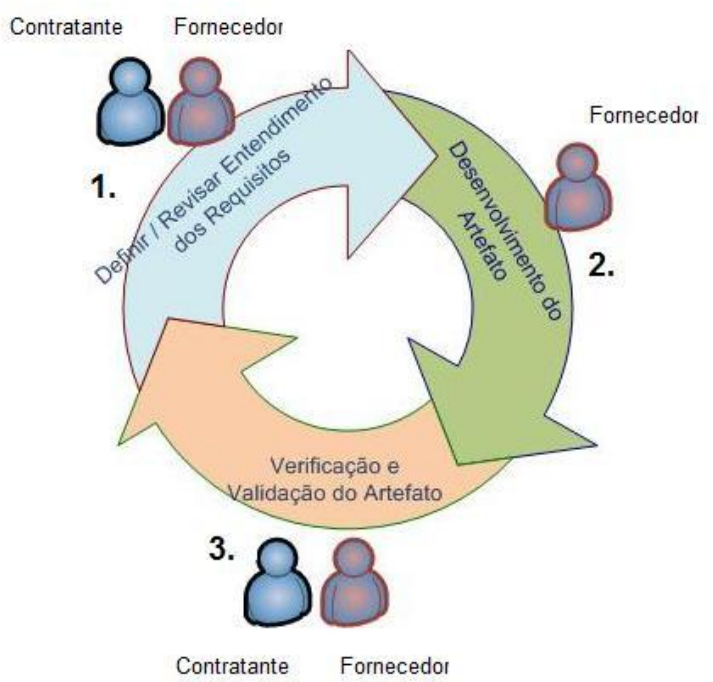

Figura 1 - Ciclo Fundamental do Processo de Monitoração da Aquisição

A cada fase do processo de desenvolvimento, uma ênfase é dada ao estabelecimento em conjunto por contratante e fornecedor do entendimento dos requisitos e dos critérios para verificação e validação a serem utilizados. O desenvolvimento dos artefatos caberá ao fornecedor, sendo monitorado e inspecionado pelo contratante. Na entrega de cada artefato, a ênfase novamente recai sobre a execução em conjunto da verificação e validação pelo contratante e fornecedor. A Figura 2 apresenta o ciclo fundamental das atividades do processo definido ao longo das fases do processo de desenvolvimento 


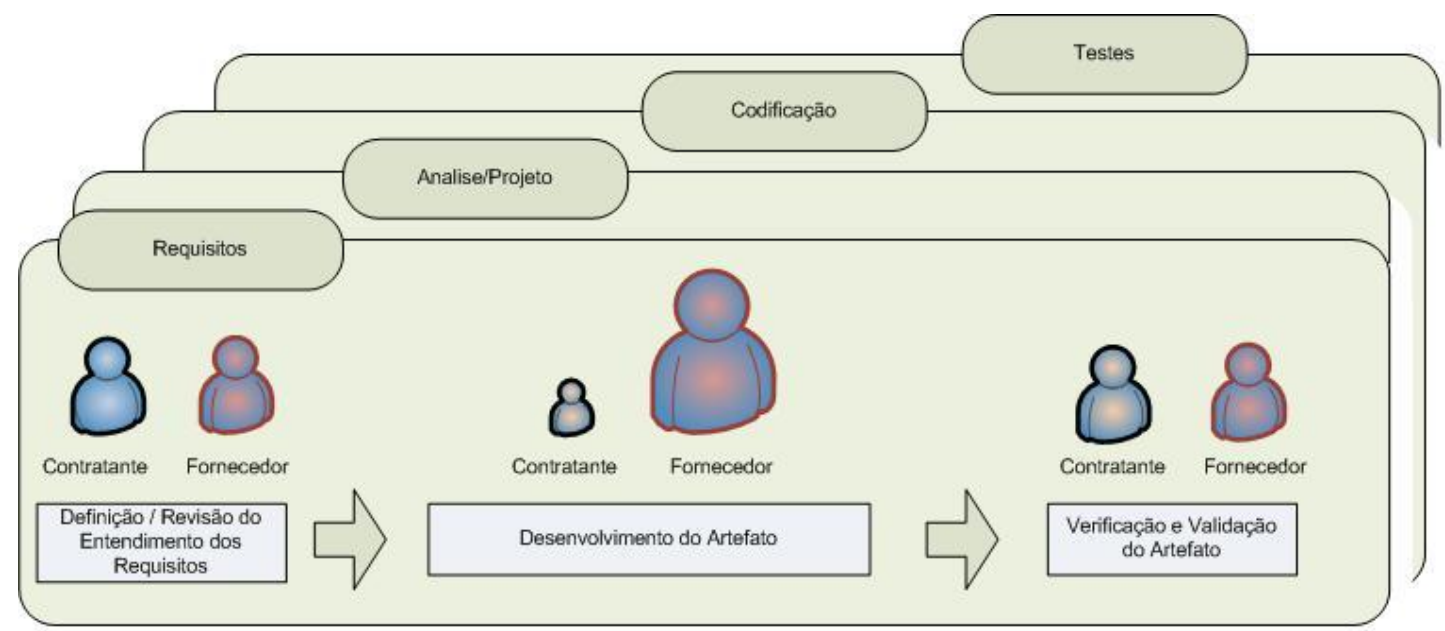

Figura 2 - Ciclo Fundamental do Processo Definido por Fase do Desenvolvimento

O estabelecimento inadequado de requisitos bem como de critérios vagos para verificação e validação podem ser vistos como algumas das causas do insucesso das aquisições de software. A monitoração de prazos, custos, resolução de problemas, ajustes contratuais e outros aspectos administrativos não ligados diretamente à elaboração dos artefatos também podem ser vistos como tarefas compartilhadas entre contratante e fornecedor. Ambos disparam ações corretivas para garantir o atendimento dos critérios de verificação e validação. Durante todo o processo de desenvolvimento, as comunicações formais e informais devem ser freqüentes, possibilitando o adequado acompanhamento do projeto.

A Figura 3 apresenta o processo de monitoração de aquisição proposto. Ele possui 6 macro-atividades: Planejar Monitoração, Definir/Revisar Entendimento dos Requisitos da Iteração, Gerenciar Monitoração, Executar Verificação e Validação, Gerenciar Ações e Mudanças e Avaliar o Processo. As macro-atividades Definir/Revisar Entendimento dos Requisitos, Gerenciar Monitoração e Executar Verificação e Validação compõem o ciclo fundamental apresentado na Figura 1. Todas as macro-atividades do processo proposto são detalhadas a seguir.

\subsection{Planejar Monitoração}

O propósito da macro-atividade Planejar Monitoração é planejar a monitoração da aquisição do desenvolvimento de software. Ela é composta pelas atividades Elaborar Plano de Monitoração, Elaborar Plano de Verificação e Validação, Revisar Entendimento do Processo e Avaliar Planejamento da Contratada. Um gerente da monitoração deve ser designado pelo contratante como responsável por essas atividades e por todo o processo de monitoração da aquisição. As habilidades e competências do gerente da monitoração devem ser semelhantes às habilidades e competências de um gerente de projeto definidas no PMBOK. A monitoração da aquisição de software pode ser comparada a um projeto, onde sua execução, seja de parte ou de todas as fases de desenvolvimento, é transferida para um fornecedor, e que o sucesso ou fracasso da iniciativa ainda depende do contratante.

A atividade Elaborar Plano de Monitoração tem como objetivo planejar a monitoração da aquisição definindo escopo, ciclo de vida, elaborando estimativas, estabelecendo marcos, cronograma, planejando recursos, infra-estrutura, identificando envolvidos, planejando comunicação, identificando e analisando riscos, planejando a gerência de dados, definindo o acordo de nível de serviço, procedimento de controle de mudanças e procedimento de tratamento 
de desvios. Uma fase de planejamento da monitoração é característica comum a vários guias, normas e modelos (SEI, 2006, 2007; ITSQC, 2006; SOFTEX, 2009; PMI, 2009). O objetivo dessa atividade é estabelecer o plano de monitoração, artefato que direcionará a execução do processo de monitoração da aquisição. $\mathrm{O}$ plano de monitoração deverá ser condizente com o porte, complexidade ou caráter estratégico da aquisição.

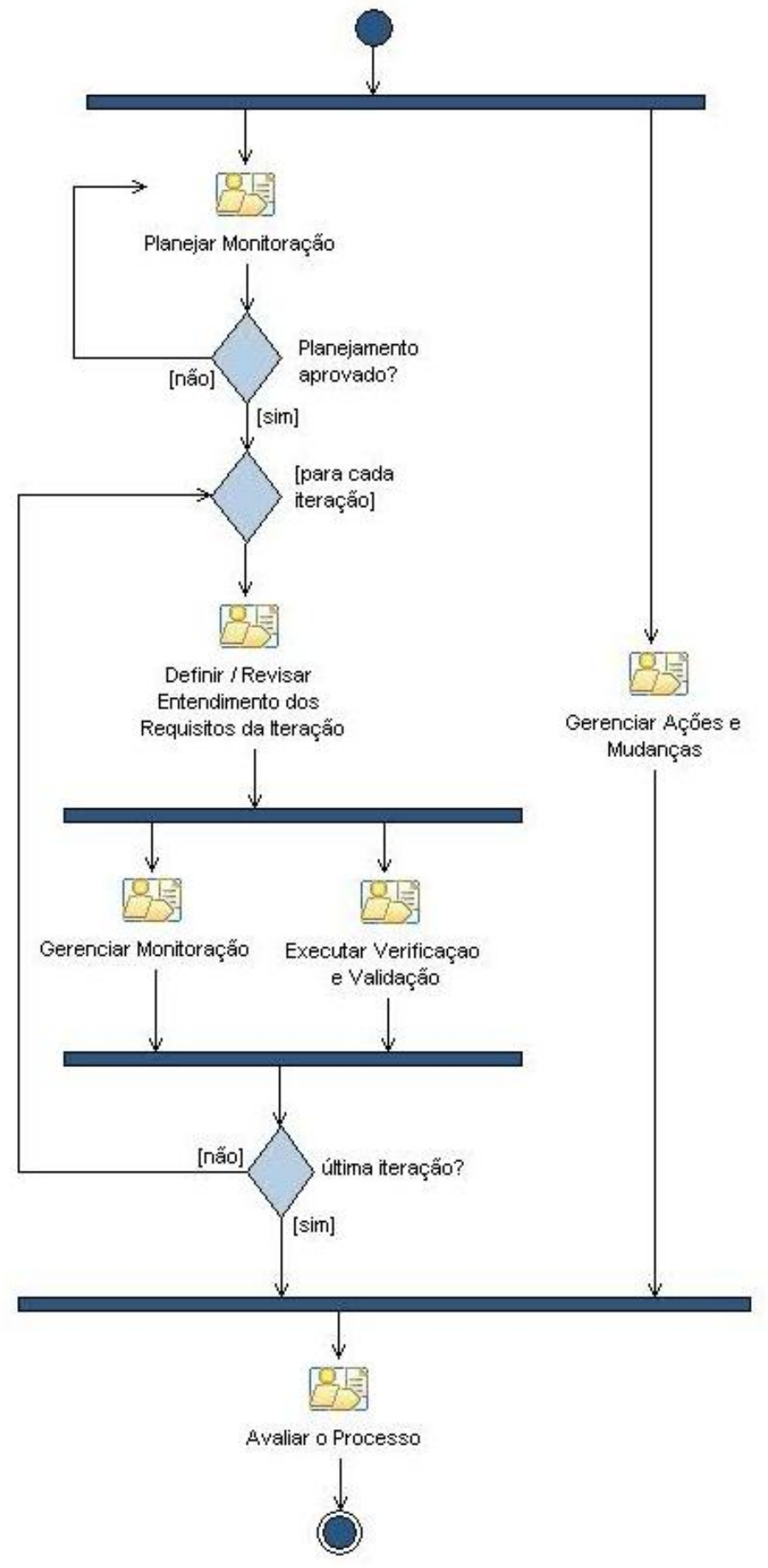

Figura 3 - Processo de Monitoração de Aquisição de Software baseado em Verificação e Validação 
A atividade Elaborar Plano de Verificação e Validação tem como objetivo planejar a verificação e validação dos artefatos do processo de monitoração da aquisição, selecionando os artefatos que serão objetos de verificação e validação, selecionando os métodos e ferramentas de verificação e validação para cada artefato selecionado, identificando os critérios de verificação e validação para cada artefato selecionado e identificando os responsáveis pela verificação e validação para cada artefato. Uma fase de planejamento da verificação e validação é característica comum a vários guias, normas e modelos (ISO 12207, 2002; SEI, 2006, 2007; SOFTEX, 2009). O objetivo dessa atividade é estabelecer o plano de verificação e validação, artefato que direcionará a execução das atividades de verificação e validação ao longo do processo de monitoração da aquisição.

A atividade Revisar Entendimento do Processo tem como objetivo revisar o entendimento do processo de monitoração da aquisição com o fornecedor apresentando o processo de monitoração, apresentando o processo de verificação e validação e obtendo o comprometimento do fornecedor com o processo de monitoração. O objetivo dessa atividade é garantir o entendimento do processo de monitoração da aquisição pelo fornecedor obtendo assim seu comprometimento. Uma vez entendido o processo, o fornecedor elabora o seu planejamento e submete ao contratante para aprovação.

A atividade Avaliar Planejamento da Contratada tem como objetivo avaliar o planejamento do fornecedor antes da execução do processo de monitoração, revisando e aprovando o planejamento definido. O objetivo dessa atividade é garantir que o planejamento da contratada está em conformidade com as necessidades da aquisição e características do processo de monitoração.

\subsection{Definir / Revisar Entendimento dos Requisitos da Iteração}

O propósito da atividade Definir/Revisar Entendimento dos Requisitos da Iteração é realizar uma revisão dos requisitos da aquisição com o fornecedor. Essa revisão permite que contratante e fornecedor estejam alinhados quanto aos requisitos que necessitam ser atendidos. $\mathrm{O}$ gerente da monitoração é o responsável por essa atividade, que também conta com a participação fundamental da equipe técnica de monitoração e do gerente e equipe técnica do fornecedor. Essa atividade acontece no início das iterações do processo de monitoração da aquisição.

No início do processo de monitoração, o que normalmente existe é uma visão geral dos requisitos. No início de cada iteração, a visão dos requisitos é detalhada e revisada de modo a permitir o maior entendimento do escopo contratado. Caso surjam pendências durante a revisão dos requisitos, um refinamento dos requisitos da aquisição deve ser realizado. No início do processo de monitoração, as incertezas em relação aos requisitos são maiores. Por esse motivo, o que for possível detalhar no início do processo maximizará a probabilidade de sucesso de atingir os objetivos da aquisição. Uma vez que não existam mais pendências e o refinamento dos requisitos tenha sido realizado, ocorre a formalização do comprometimento do fornecedor com os requisitos da aquisição. Embora o comprometimento com a aquisição seja formalizado em tempo de assinatura do contrato, nesse momento o grau de incerteza em relação ao entendimento dos requisitos é grande, pois normalmente o foco é maior em aspectos administrativos do que técnicos. Durante a monitoração, onde o foco maior é técnico, o comprometimento com partes menores do escopo permite seu melhor entendimento e dimensionamento.

O processo de monitoração de aquisição de software necessita que requisitos sejam previamente definidos. O nível de detalhamento inicial dos requisitos varia de acordo com o tipo de 
contrato definido para a aquisição. Os tipos de contrato mais utilizados são: preço fixo, homemhora e baseado em métrica de tamanho. No contrato preço fixo, onde um preço é definido para um escopo ser entregue em determinado prazo, é recomendado que os requisitos estejam bem detalhados, de forma ideal, até as especificações de casos de uso. Nesse caso, ou a equipe técnica do contratante executa esse trabalho internamente, caso essa equipe exista ou esteja disponível, ou o adquirente contrata um fornecedor para elaboração dos requisitos e casos de uso do projeto. No contrato homem-hora, onde o valor total corresponde ao preço das horas trabalhadas pelo fornecedor, é possível iniciar a monitoração com os requisitos pouco detalhados. Nesse caso, a equipe técnica do contratante e a equipe técnica do fornecedor podem trabalhar juntas ao longo da monitoração da aquisição no detalhamento dos requisitos e casos de uso. No contrato baseado em métrica de tamanho, onde o valor total corresponde ao preço do tamanho do escopo baseado em uma métrica, por exemplo, Ponto de Caso de Uso Técnico - TUCP, é recomendado que os requisitos estejam no nível de detalhamento que possibilite a mensuração do tamanho do escopo adquirido (MONTEIRO, 2005). A situação ideal é detalhar os requisitos até as especificações de casos de uso mas também é possível trabalhar com uma estimativa inicial baseada em um nível de detalhamento menor, considerando que reavaliações ao longo do processo de monitoração podem ser necessárias.

\subsection{Gerenciar Monitoração}

O propósito da macro-atividade Gerenciar Monitoração é gerenciar a monitoração da aquisição de desenvolvimento de software através do acompanhamento do seu progresso, processos e possíveis desvios em relação ao planejamento da monitoração. Ela é composta pelas atividades Monitorar Progresso da Aquisição, Monitorar Processos do Fornecedor e Tratar Desvios. Uma fase de gerenciamento da monitoração é característica comum a vários guias, normas e modelos (SEI, 2006, 2007; ITSQC, 2006; SOFTEX, 2009; PMI, 2009). O gerente da monitoração é o responsável por essas atividades, que também conta com a participação fundamental da equipe técnica de monitoração. Essas atividades acontecem ao longo da execução do processo de monitoração da aquisição.

$\mathrm{Na}$ atividade Monitorar Progresso da Aquisição, o gerente e a equipe de monitoração monitoram o progresso da aquisição através do acompanhamento do prazo, custos, escopo, qualidade e riscos, além de realizar reuniões de acompanhamento técnicas e gerenciais.

$\mathrm{Na}$ atividade Monitorar Processos do Fornecedor, o gerente e a equipe de monitoração monitoram os processos do fornecedor através da avaliação de processos e de reuniões de acompanhamento de qualidade.

A atividade Tratar Desvios tem como objetivo tratar os desvios identificados nas atividades Monitorar Progresso da Aquisição e Monitorar Processos do Fornecedor. Caso os indicadores de desempenho do progresso e dos processos não estejam de acordo com o planejado ou estejam com tendência de desviarem do planejado no acordo de nível de serviço, ações corretivas e preventivas são disparadas, respectivamente. Outra possibilidade é de solicitações de mudança serem disparadas para tratar desvios que provoquem alterações no planejamento aprovado.

\subsection{Executar Verificação e Validação}

O propósito da atividade Executar Verificação e Validação é executar verificação e validação dos artefatos gerados pela contratada, previstos no processo de monitoração da 
aquisição. Ao longo da monitoração, a equipe da monitoração deverá verificar e validar os produtos de trabalho gerados pelo fornecedor de acordo com os métodos, ferramentas e critérios definidos no plano de verificação e validação. Uma fase de verificação e validação é característica comum a vários guias, normas e modelos (ISO 12207, 2002; SEI, 2006, 2007; SOFTEX, 2009). Essa atividade permitirá que os resultados gerados pelo fornecedor sejam acompanhados de maneira incremental pelo contratante, minimizando assim, desvios em relação ao planejamento e maximizando o atendimento das necessidades da aquisição. A equipe técnica de monitoração é a responsável por essa atividade.

Revisões técnicas são realizadas utilizando inspeções e walkthrough, dentre outras técnicas (BARRETO, 2006). Essas revisões verificam e validam resultados não-executáveis gerados pelo fornecedor, tais como especificações de casos de uso, especificação de arquitetura, modelos de análise e projeto e especificações de casos de testes.

Existem várias fases de testes ao longo de um processo de desenvolvimento de software (BARRETO, 2006). A primeira fase consiste no teste de unidade ou teste unitário. Nessa fase, cada unidade do software é testada isolada das demais unidades do sistema. A segunda fase consiste no teste de integração. Após as unidades terem sido testadas, essa fase assegura que as interfaces entre as unidades foram definidas e tratadas adequadamente. A terceira fase é o teste do sistema ou teste sistêmico. Essa fase assegura que o sistema possui a funcionalidade desejada. $\mathrm{O}$ teste do sistema é formado ainda pelo teste funcional, teste de desempenho, teste de aceitação e teste de instalação (PFLEEGER, 2004).

No contexto de monitoração de aquisição de software, normalmente o fornecedor será responsável pelos testes de unidade e pelos testes de integração. Os testes sistêmicos poderão ser de responsabilidade do fornecedor e/ou do contratante, dependendo do escopo da aquisição. Se o escopo da aquisição incluir a fase de testes, caberá ao fornecedor, além da execução dos testes de unidade e de integração, a execução dos testes sistêmicos funcionais, testes sistêmicos de desempenho e testes sistêmicos de instalação. Nesse caso, caberá ao contratante apenas os testes sistêmicos de aceitação. Se o escopo da aquisição não incluir a fase de testes, caberá ao fornecedor a execução dos testes de unidade e de integração, e caberá ao contratante a totalidade dos testes sistêmicos, compostos pelo teste funcional, teste de desempenho, teste de aceitação e teste de instalação.

\subsection{Gerenciar Ações e Mudanças}

O propósito da atividade Gerenciar Ações e Mudanças é gerenciar as ações corretivas, preventivas e solicitações de mudança disparadas durante o processo de monitoração da aquisição. O gerenciamento de ações e mudanças é característica comum a vários guias, normas e modelos (ISO 12207, 2002; SEI, 2006, 2007; ITSQC, 2006; SOFTEX, 2009; PMI, 2009). O gerente da monitoração é o responsável por essa atividade, que acontece ao longo da execução do processo de monitoração da aquisição.

Os planos de ações preventivas e corretivas são implementados nessa atividade. As solicitações de mudança devem ser analisadas e seus impactos nos objetivos da monitoração mensurados. Caso a solicitação de mudança seja aprovada, a mesma deve ser implementada de acordo com os resultados da análise de impacto. Planos de ações corretivas e preventivas gerados durante o processo de monitoração devem ser implementados. 


\subsection{Avaliar o Processo}

O propósito da atividade Avaliar o Processo é avaliar a execução do processo de monitoração da aquisição. Lições aprendidas do processo de monitoração devem ser identificadas, uma análise post-mortem e uma reunião de encerramento devem ser realizadas, e a base histórica deve ser atualizada. Uma fase de avaliação do processo é característica comum ao PMBOK (PMI, 2009). O gerente da monitoração é o responsável por essa atividade, que também conta com a participação fundamental da equipe técnica de monitoração. Essa atividade acontece no final do processo de monitoração da aquisição e tem como objetivo coletar informações que permitam a melhoria contínua da execução dos processos de monitoração da aquisição pelo contratante.

\section{Avaliação Preliminar do Processo}

Após a definição do processo de monitoração de aquisição baseado em verificação e validação, iniciou-se a aplicação do processo em uma experiência de uso real. Entretanto, em virtude de atraso no início do processo de monitoração da aquisição na organização escolhida, essa aplicação apresentaria dados apenas da atividade de planejamento do processo. Dessa maneira, utilizou-se outra abordagem para avaliação do processo. Foi elaborado e aplicado um questionário para avaliação do processo por especialistas de reconhecida competência na área de tecnologia da informação e comunicação.

\subsection{Metodologia}

O questionário foi elaborado considerando vários problemas enfrentados por contratantes e fornecedores no contexto de monitoração de aquisição de software. Especialistas responderam ao questionário ratificando ou não se os problemas identificados realmente eram problemas enfrentados por contratantes e fornecedores de serviços de software e observando se o processo definido contribuiu para o atendimento desses problemas. Foram exemplos de problemas identificados: a falta de envolvimento do contratante na definição dos requisitos, a falta de envolvimento do contratante na verificação e validação dos artefatos e do software, a falta de correspondência entre os requisitos especificados e o produto entregue ao contratante, a falta de correspondência entre os requisitos especificados e a verificação e validação, a falta de planejamento da monitoração da aquisição, a não monitoração realizada em pequenos intervalos de tempo (iterações) e a falta de acompanhamento das estimativas de esforço, prazo e custo. A pesquisa contou com as seguintes etapas: seleção da amostra, convocação dos entrevistados, coleta dos dados e análise dos dados.

A seleção da amostra foi realizada de forma que a amostra escolhida representasse um grupo altamente qualificado de profissionais com larga experiência na área de tecnologia da informação e comunicação. Foram selecionados 6 profissionais de importantes organizações contratantes e fornecedoras de serviços de software do estado do Ceará.

A convocação dos entrevistados foi realizada pessoalmente. No momento da convocação, foi explicado o objetivo e a dinâmica da pesquisa. Primeiramente, uma apresentação do processo de monitoração da aquisição de software baseado em verificação e validação foi realizada para cada entrevistado. Após a apresentação do processo, o entrevistado preencheu o questionário sem qualquer tipo de influência.

A coleta de dados foi realizada obtendo dos entrevistados respostas para cada uma das questões de acordo com a seguinte escala: (DF) Discordo Fortemente, (D) Discordo, (N) Nem Concordo Nem Discordo, (C) Concordo e (CF) Concordo Fortemente. Após o término do 
preenchimento dos questionários, os dados foram tabulados. Para cada questão foi contabilizado o número de notas por tipo.

A análise dos resultados foi realizada quantitativa e qualitativamente. Para cada questão foi gerado um gráfico representando a totalização do percentual de notas por tipo. Através dos valores obtidos pôde-se concluir a opinião dos especialistas sobre o processo apresentado. Além da análise quantitativa foi possível realizar uma análise qualitativa a partir dos comentários, pontos fortes, pontos fracos e oportunidades de melhoria identificadas pelos entrevistados (ABREU, 2009).

\subsection{Resultados}

Os resultados mostraram que $100 \%$ dos entrevistados concordaram fortemente que a falta de envolvimento do contratante na definição dos requisitos acarreta problemas no contexto de monitoração de aquisição de software e que $100 \%$ dos entrevistados ou concordaram fortemente (67\%) ou concordaram (33\%) que o processo avaliado contribuiria para minimizar esse problema enfatizando a participação, co-responsabilidade e necessidade de alocação de recursos de contratante e fornecedor para a definição/entendimento em conjunto dos requisitos através das atividades de Planejar Monitoração e Definir/Revisar Entendimento dos Requisitos da Iteração.

Os resultados mostraram que $100 \%$ dos entrevistados concordaram fortemente que a falta de envolvimento do contratante na verificação e validação dos artefatos e do software acarreta problemas no contexto de monitoração de aquisição de software e que $100 \%$ dos entrevistados ou concordaram fortemente $(67 \%)$ ou concordaram $(33 \%)$ que o processo avaliado contribuiria para minimizar esse problema, planejando a alocação dos recursos necessários do contratante e prevendo sua utilização através das atividades Planejar Monitoração e Executar Verificação e Validação.

Os resultados mostraram que $83 \%$ dos entrevistados concordaram fortemente que a falta de correspondência entre os requisitos especificados e o produto entregue ao contratante, e que $100 \%$ dos entrevistados ou concordaram fortemente $(67 \%)$ ou concordaram $(33 \%)$ que a falta de correspondência entre os requisitos especificados e a verificação e validação feita pelo contratante acarretam problemas no contexto de monitoração de aquisição de software. Os resultados mostraram ainda que $100 \%$ dos entrevistados ou concordaram fortemente $(50 \%)$ ou concordaram $(50 \%)$ que o processo avaliado contribuiria para minimizar esse problema enfatizando a participação e co-responsabilidade de contratante e fornecedor na definição de critérios objetivos de verificação e validação dos artefatos, definição/entendimento em conjunto dos requisitos e execução de revisões e testes dos artefatos através das atividades Planejar Monitoração, Definir/Revisar Entendimento dos Requisitos da Iteração e Executar Verificação e Validação.

Os resultados mostraram que $100 \%$ dos entrevistados ou concordaram fortemente (33\%) ou concordaram (67\%) que a falta de planejamento da monitoração da aquisição acarreta problemas no contexto de monitoração de aquisição de software e que $100 \%$ dos entrevistados ou concordaram fortemente $(83 \%)$ ou concordaram $(17 \%)$ que o processo avaliado contribuiria para minimizar esse problema definindo a atividade Planejar Monitoração especificamente com essa finalidade.

Os resultados mostraram que $100 \%$ dos entrevistados ou concordaram fortemente (83\%) ou concordaram (17\%) que a monitoração não ser realizada em pequenos intervalos de tempo (iterações) acarreta problemas no contexto de monitoração de aquisição de software e que $66 \%$ dos entrevistados ou concordaram fortemente $(33 \%)$ ou concordaram $(33 \%)$ que o processo 
avaliado contribuiria para minimizar esse problema, prevendo que as atividades Definir/Revisar Entendimento dos Requisitos da Iteração, Gerenciar Monitoração e Executar Verificação e Validação ocorrem em ciclos iterativos.

Os resultados mostraram que $83 \%$ dos entrevistados concordaram fortemente que a falta de acompanhamento das estimativas de esforço, prazo e custo acarreta problemas no contexto de monitoração de aquisição de software e que $100 \%$ dos entrevistados ou concordaram fortemente $(67 \%)$ ou concordaram (33\%) que o processo avaliado contribuiria para minimizar esse problema, prevendo que a atividade Gerenciar Monitoração possui tarefas específicas para essa finalidade.

$\mathrm{Na}$ aplicação do questionário, vários comentários foram feitos pelos entrevistados sobre problemas enfrentados por contratantes e fornecedores no contexto de monitoração de aquisição de software, e foram identificados pontos fortes, pontos fracos e oportunidades de melhoria para $\mathrm{o}$ processo (ABREU, 2009).

\section{Conclusões e Trabalhos Futuros}

As atividades de definição de requisitos bem como a atividade de verificação e validação têm merecido uma atenção especial no contexto de desenvolvimento de software. No contexto de aquisição de software, a participação do contratante nessas atividades é fundamental visto que elas marcam, respectivamente, o início e o final do processo de desenvolvimento. Não é efetivo realizar a definição dos requisitos e a verificação e validação dos produtos gerados sem a participação do contratante. Este trabalho apresentou um processo de monitoração da aquisição de software, baseado nos principais guias, normas e modelos que definem um conjunto de boas práticas e recomendações para o ambiente de aquisições de software.

Os principais diferenciais do processo definido são:

- Foco na fase de monitoração da aquisição. A celebração do contrato marca o início das atividades do fornecedor. A partir desse marco, será requerido o maior esforço por parte do contratante e, por isso, este necessita de processos que o apóiem na monitoração do fornecedor;

- Importância dada às atividades de definição de requisitos e de verificação e validação dos produtos gerados. Essas atividades são fundamentais para que contratante e fornecedor estejam alinhados quanto aos objetivos e resultados do processo de monitoração. $\mathrm{O}$ processo destaca fortemente a necessidade do envolvimento do contratante nessas atividades, para garantir que aquilo que foi definido corresponderá ao que será verificado e validado. O contratante deve estar ciente que é necessária a alocação de recursos internos para monitoração da aquisição. A co-responsabilidade entre contratante e fornecedor ao longo de todo o processo de monitoração é fator chave para o sucesso de uma estratégia de aquisição;

- Utilização de uma abordagem iterativa, baseada em ciclos de pequenos intervalos de tempo, como forma de permitir um acompanhamento mais efetivo da monitoração, definição dos requisitos e aceitação dos produtos de trabalhos.

As principais contribuições desse trabalho foram:

- Identificação das atividades cuja participação do contratante é fundamental no processo de monitoração da aquisição de software;

- Formalização de um processo de monitoração da aquisição de serviços de software; 
- Criação de modelos de documentos que auxiliem a utilização do processo por organizações contratantes da área de TIC.

Os seguintes trabalhos futuros são sugeridos:

- Executar experiências de uso reais com objetivo de coletar lições aprendidas para melhoria contínua do processo;

- Elaborar guias de adaptação do processo definido para vários de tipos de aquisição de software, baseando-se, por exemplo, no porte, no ciclo de vida, estrutura organizacional, dentre outros critérios;

- Explorar a relação entre os acordos de nível de serviço e a aceitação dos produtos de trabalho em aquisição de software, buscando a identificação dos indicadores mais utilizados, lições aprendidas e seus valores reconhecidos como padrões científicos e de mercado, e a definição de modelos que permitam a sua utilização por organizações contratantes de software.

\section{Referências}

ABREU, F.P., 2009, Uma Abordagem Baseada em Definição de Requisitos e em Verificação e Validação para o Processo de Monitoração de Aquisição de Software, Dissertação de Mestrado, Universidade de Fortaleza, Agosto.

ABREU, F.P., FARIAS, P.P.M., ALBUQUERQUE, A.B., 2009, Um Processo Baseado em Verificação e Validação para Monitoração de Aquisição de Software, XXXV Conferência LatinoAmericana de Informática, Setembro.

ABREU, F.P., FARIAS, P.P.M., ALBUQUERQUE, A.B., 2009, A Process to Monitor the Software Acquisition Based on Verification and Validation, Conference on Research and Practical Issues of Enterprise Information System, October.

ALVES, A.M., GUERRA, A.C., 2004, Aquisição de Produtos e Serviços de Software, Rio de Janeiro, Elsevier, 213p.

BARRETO, A.O.S., 2006, Apoio à Verificação de Software em Ambientes de Desenvolvimento de Softwares Orientados à Organização, Dissertação de Mestrado, Universidade Federal do Rio de Janeiro.

CARDOSO, G.S. 2006, Processo de Aquisição de Produtos e Serviços de Software para Administração Pública do Estado de Minas Gerais, Dissertação de Mestrado, Universidade Federal de Minas Gerais, Junho.

ISO/IEC 12207, 2002, The International Organization for Standardization and The International Electrotechnical Commission, Information Technology - Software Life Cycle Processes.

ISO/IEC 15504, 2002, The International Organization for Standardization and The International Electrotechnical Commission, Information Technology - Software Process Assessment.

ITSQC, 2006, The eSourcing Capability Model for Client Organizations - eSCM-CL v1.1: Model Overview. CMU-ITSQC-06-002, IT Services Qualification Center, Carnegie Mellon University, Pittsburgh, PA, September. 
ITSQC, 2006, The eSourcing Capability Model for Service Providers - eSCM-SP v2.01: Model Overview. CMU-ITSQC-06-006, IT Services Qualification Center, Carnegie Mellon University, Pittsburgh, PA, December.

MATIELLO-FRANCISCO, M.F., SANTIAGO JR., V.A., AMBRÓSIO, M., COSTA, R., LEISE, J., 2006, Verificação e Validação na terceirização de software embarcado em aplicações espaciais. V Simpósio Brasileiro de Qualidade de Software.

MONTEIRO, T.C., 2005, Pontos de Caso de Uso Técnico (TUCP): Uma Extensão da UCP. Dissertação de Mestrado, Universidade de Fortaleza.

PFLEEGER, S.L., 2004, Engenharia de Software - Teoria e Prática, 2a .edição, Prentice Hall, São Paulo, Brasil.

PINHEIRO, L.N., 2006, Um Processo de Apoio à Gerência de Aquisição de Produtos e Serviços de Software. Dissertação de Mestrado, Universidade Federal do Rio de Janeiro, Março.

PMI, 2009, A Guide to the Project Management Body of Knowledge - PMBOK Guide, 4rd Edition. ANSI/PMI 99-001-2008, ISBN 978-1-933890, Project Management Institute.

SEI, 2006, CMMI for Development, Version 1.2. CMU/SEI-2006-TR-008, Software Engineering Institute, Carnegie Mellon University, Pittsburg, PA, August.

SEI, 2007, CMMI for Acquisition, Version 1.2. CMU/SEI-2007-TR-017, Software Engineering Institute, Carnegie Mellon University, Pittsburg, PA, November.

SOFTEX, 2009, MPS.BR - Melhoria de Processo do Software Brasileiro, Guia Geral, SOFTEX, Maio.

SOFTEX, 2009, MPS.BR - Melhoria de Processo do Software Brasileiro, Guia de Implementação - Parte 4: Nível D, SOFTEX, Maio.

STANDISH, 2009, Chaos Summary Report, Standish Group, Boston, Massachusetts, April. 